\section{Saskatchewan successfully}

\section{implementing best practices}

$\mathrm{O}$ ne-quarter of family physicians in Saskatchewan have volunteered to participate in a groundbreaking initiative to implement best practices in the treatment of diabetes and coronary artery disease.

After one year, the Chronic Disease Management Collaborative reports an increase in the number of patients receiving the recommended drugs, tests and services, and a decrease in the time they wait to see their family physicians. For example, the number of patients with diabetes receiving annual kidney screening jumped from $48 \%$ to $68 \%$, and the number of patients receiving antiplatelet therapy for coronary artery disease rose from $73 \%$ to $82 \%$.

In one family practice in Saskatoon, the wait time for an appointment dropped from 17 to 3 days and a backlog of roo annual check-ups was cleared in 5 months.

"It is clear that these efforts are helping to turn the tide on chronic disease in Saskatchewan," said Dr. Ben Chan, CEO of the Health Quality Council, an independent agency of the provincial department of health. The council is using a collaborative approach to set benchmarks and share effective strategies among 73 family practices across Saskatchewan, involving 216 family physicians, 400 other health care professionals and more than 12 ooo patients.

"There isn't a collaborative initiative across the country of the scale that we are doing in Saskatchewan, and we were purposeful about that scale because we wanted to reach the tipping point. We wanted to go big," said Bonnie Brossart, deputy CEO of the Health Quality Council.

Representatives of each family practice attend 4 workshops during the year where they "share nuggets of what works and what doesn't work, and through that sharing, we're seeing a rapid improvement in results," said Brossart.

Patient data is entered into an electronic toolkit that lists the recommended best practices for each disease and tracks implementation. This Webbased toolkit allows physicians to cre- ate flowcharts, measure progress, create reports and share information electronically with other health professionals, patients and the council.

The workshops were held in 2 stages during 2005-06 and 2006-07; data presented here are based on the first wave.

"In Saskatchewan, we have a shortage of physicians so you're always overworked and acute patients take up much of your time," says Vino Padayachee, a family physician from Estevan and chair of the Chronic Disease Management Collaborative. "We're making a concerted effort to bring chronic disease into the forefront. We will save money and time in the long run."

Padayachee says the Saskatchewan Medical Association is working with the provincial government to increase physician fees for chronic disease management.

To qualify, physicians will be required to follow best practice guidelines and document the results. - Amy Jo Ehman, Saskatoon, Sask.

DOI:Io.I503/cmaj.070329

\section{New deputy editor dedicated}

\section{to knowledge transfer}

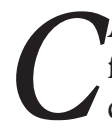

$M A J$ has revitalized its research focus with the appointment of a deputy editor for scientific content. Dr. Matthew Stanbrook, an assistant professor, researcher and specialist in respirology at the Toronto Western Hospital, will oversee reviews and research - including his own.

"The idea is to shape and build this core component of the journal," says Stanbrook, who is also an assistant professor of Medicine and Health Policy, Management and Evaluation at the University of Toronto. This includes encouraging publication of more randomized trials and increasing the quality of research and its relevancy to readers.

"We are very fortunate to have someone of Matthew's calibre join our team," says CMAJ Editor-in-Chief Dr. Paul Hébert. "He will substantially enhance the science we publish."

The move to $C M A J$ is a natural pro- gression for Stanbrook whose longtime passion for publications began with the University of Toronto Medical Journal, where he was associate editor in 1992 and then editor-in-chief. "I got the bug early on," he laughs

After completing residencies in internal medicine and respirology at the University of Toronto, Stanbrook began a doctorate in clinical epidemiology. He asked respirologist Dr. Jeff Drazen, editor-in-chief at the New England Journal of Medicine, to take him on for a year so could look at the ways medical journals influence knowledge translation and research. For Stanbrook, Drazen created the editorial fellowship, a position that continues today.

At the time Stanbrook assumed his position at CMAJ on Feb. I9, he was a peer reviewer for 5 journals, an editorial board member of Clinical and Investigative Medicine and an associate editor of ACP Journal Club. He has nearly 40 publication credits to his name and has received several awards and scholarships, including the University of Toronto's respirology teaching award (2004).

His new position with $C M A J$ is an opportunity to "expand on my thesis and look at how medical journals influence patient outcomes."

Stanbrook will be looking at ways of presenting information, such as Web casts, that bolster its relevancy to Canadian and international readers.

Data show that $C M A J$ is increasingly

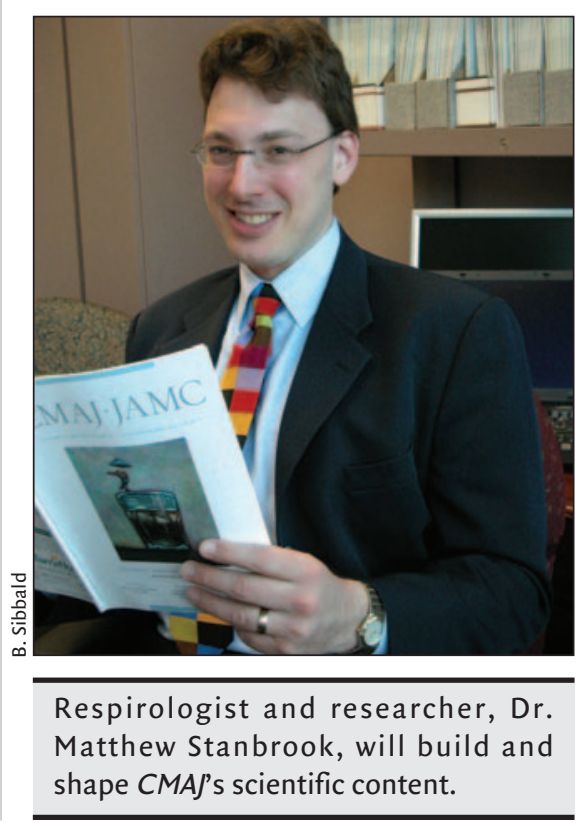

